\title{
An investigation on dimensional accuracy of EDM deep hole using multi-hole interior flushing electrode
}

\author{
Suppawat Chuvaree and Kannachai Kanlayasiri* \\ Industrial Engineering Department, Faculty of Engineering, King Mongkut's Institute of Technology Ladkrabang, Bangkok, Thailand
}

\begin{abstract}
Improper flushing of dielectric fluid adversely affects the dimensional accuracy produced in EDM deep hole process. This paper investigates the dimensional accuracy (e.g. roundness error and gap clearance) in EDM deep hole process of AISI P20 tool steel. The inner flushing electrode is newly proposed in this study, using the multi-hole interior flushing technique coupled with electrode rotation. The results showed that the multi-hole interior flushing with electrode rotation improves the deviation of roundness error due to improved flushing. In addition, using multi-hole interior flushing with electrode rotation provides the cylindrical shape in gap clearance. Finally, a more powerful flushing technique is achieved with newly purposed multi-hole interior flushing technique on roundness error and gap clearance, respectively.
\end{abstract}

\section{Introduction}

Electrical discharge machining (EDM) is finding a lot of applications for machining certain materials which traditionally have been more difficult to machine. Such developments further enable the growing demand of higher precision parts, for advancements in automotive and other industries [1]. The dimensions and accuracies resultant on machined a hole by EDM process plays a crucial role when close tolerance components are required for critical applications like plastic mould and die part, automotive part etc. During EDM of a deep hole, machining conditions can be optimized leading to high process accuracy and greater machining productivity. However, the flushing stage has been identified as the most important factor in the determining the dimensional accuracy [2-3]. In an Electrical discharge machining operation, the flushing function is employed to remove the debris in the machining gap and to sustain the dielectric temperature well below its flash point. In addition, the influence of electrode rotation coupled with the flushing technique can increase the material removal rate (MRR), assisting the removal of the debris and assuring that the hole is round [4].

During the EDM process both the workpiece and tool electrode are eroded simultaneously. When the machining depth is increased, the viscous resistance within the machining gap impedes in removal of debris and bubbles from the eroding area resulting in reduced extensive performance and dimensional accuracy. This debris activation and secondary spark appearance on the wall, result in a machined hole that is not ideally cylindrical but concaved and tapered, which is undesirable in the precision machining processes.
The study of the surface and accuracies produced during EDM with rotating electrode have been reported in [5]. It found that the electrode rotation improves the surface finish and roundness. Diver et al. [6] developed a new flushing technique to produce reverse tapered micro-holes. Excellent hole formation with hole diameter variations within $3 \mu \mathrm{m}$ were reported.

Recently the authors [7] developed a new technique of flushing for deep hole by using a multi-hole interior flushing electrode. We found that flushing through the tool electrode and multi-hole interior flushing are more preferred than side flushing. In addition, the effects of improved flushing increases material removal rate and reduces machining time. Therefore, in this paper, an attempt has been made to investigate dimensional accuracy characteristics of deep holes produced by EDM using multi-hole interior flushing technique like roundness error and gap clearance, respectively.

\section{Experiment}

In this research, the electrode was designed with regard to improved flushing ability to reduce the error of hole dimensions caused by EDM condition and improper flushing. As shown in Figure 1, the copper electrode of diameter $12 \mathrm{~mm}$, and $8.4 \mathrm{~mm}$. in flushing hole. In addition, the electrode rotation helps in flushing away debris, preventing secondary spark phenomena and enhancing the performance of EDM process.

Figures 2a shows the machined workpieces after deep holes machining. To investigate the influence of flushing condition on roundness error and gap clearance, we considered an electrode rotation at $105 \mathrm{rpm}$ and a fixed machining depth of $50 \mathrm{~mm}$ 


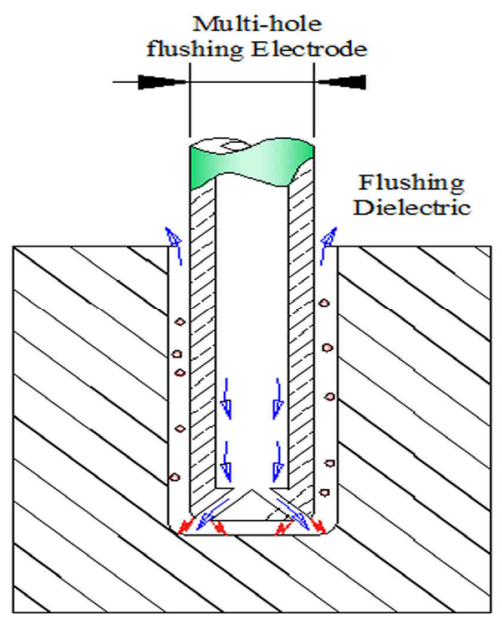

Fig. 1. Tool electrode and flushing system.

The dimensional accuracy was tested at six locations $(1,10,20,30,40$, and $50 \mathrm{~mm})$ through the machining direction as shown in figure $2 \mathrm{~b}$. The precision measurements of roundness error of the hole were analyzed from 3D surface roughness, Olympus model LEXT OLS5000 laser scanning confocal microscope noncontact. The measurement of roundness error of the hole profile was defined by maximum inscribed circle (LSC) method according to GD\&T methodology. Whereby, least square circle, it is a circle which separates the roundness profile of an object by separating the sum of total areas of the inside and outside it in equal amounts. The roundness error then can be estimated difference between the maximum and minimum distance from this reference circle. So, the roundness error is defined as equation (1).

$$
\text { Roundness }=\mathrm{R}_{\max }-\mathrm{R}_{\min }
$$

The gap clearance profiles were examined using a laser scanning model Creaform REV scan 3D handy scanner. The technical specifications are given in Table 1.

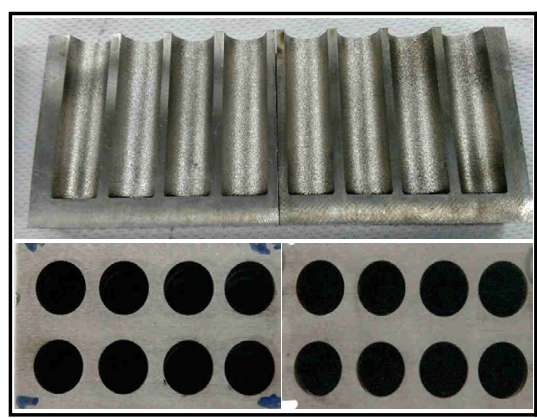

a)

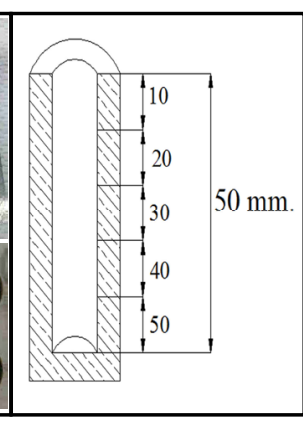

b)
Fig. 2 a) AISI P20 tool steel workpieces after deep hole machining. workpiece.
Table 1. Experimental conditions.

\begin{tabular}{|c|c|}
\hline Process parameters & Values \\
\hline $\begin{array}{c}\text { Pulse on-time } \\
\text { Pulse off-time }\end{array}$ & $\begin{array}{c}150 \mu \mathrm{s} . \\
20 \mu \mathrm{s} .\end{array}$ \\
\hline Peak current & $15 \mathrm{~A}$. \\
\hline Electrode diameter & $12 \mathrm{~mm}$. \\
\hline Electrode polarity & + \\
\hline Machining depth & $50 \mathrm{~mm}$. \\
\hline Dielectric & $\begin{array}{c}\text { EDM oil-TOTAL } \\
\text { DIET MS 700 }\end{array}$ \\
\hline Flushing pressure & $1 \mathrm{~kg} / \mathrm{cm}^{2}$ \\
\hline Workpiece Material & AISI P20 \\
\hline
\end{tabular}

\section{Results and Discussion}

\subsection{Roundness}

In this experiment, the electrode rotation and flushing mode using a multi-hole interior flushing technique are used to investigate the effect of dimensional accuracy in terms of roundness error of the hole. In the roundness measurement operation, the results of the deviation of roundness error when using conventional flushing and multi-hole interior flushing electrode are shown in Table 2 and 3 respectively.

Table 2. The deviation of roundness error when using conventional flushing with electrode rotation.

\begin{tabular}{|c|c|c|c|c|}
\hline $\begin{array}{c}-\mathrm{Z} \\
\text { position }\end{array}$ & $\begin{array}{c}\text { Diameter } \\
\text { of hoe } \\
\text { (mm.) }\end{array}$ & $\begin{array}{c}\text { Max. } \\
\text { Deviation } \\
\text { (mm.) }\end{array}$ & $\begin{array}{c}\text { Min. } \\
\text { Deviation } \\
(\mathrm{mm} .)\end{array}$ & $\begin{array}{c}\text { Range } \\
(\mathrm{mm} .)\end{array}$ \\
\hline-1 & 12.327 & 0.026 & -0.035 & 0.061 \\
\hline-10 & 12.543 & 0.040 & -0.057 & 0.097 \\
\hline-20 & 12.545 & 0.048 & -0.061 & 0.109 \\
\hline-30 & 12.530 & 0.061 & -0.059 & 0.120 \\
\hline-40 & 12.440 & 0.076 & -0.098 & 0.174 \\
\hline-50 & 12.263 & 0.096 & -0.151 & 0.247 \\
\hline
\end{tabular}

Table 3. The deviation of roundness error when using multi-hole interior flushing electrode with electrode rotation.

\begin{tabular}{|c|c|c|c|c|}
\hline $\begin{array}{c}-Z \\
\text { position }\end{array}$ & $\begin{array}{c}\text { Diameter } \\
\text { of hoe } \\
(\mathrm{mm} .)\end{array}$ & $\begin{array}{c}\text { Max. } \\
\text { Deviation } \\
(\mathrm{mm} .)\end{array}$ & $\begin{array}{c}\text { Min. } \\
\text { Deviation } \\
(\mathrm{mm} .)\end{array}$ & $\begin{array}{c}\text { Range } \\
(\mathrm{mm} .)\end{array}$ \\
\hline-1 & 12.220 & 0.057 & -0.066 & 0.123 \\
\hline-10 & 12.350 & 0.063 & -0.070 & 0.133 \\
\hline-20 & 12.416 & 0.074 & -0.047 & 0.121 \\
\hline-30 & 12.490 & 0.048 & -0.061 & 0.109 \\
\hline-40 & 12.409 & 0.059 & -0.048 & 0.107 \\
\hline-50 & 12.152 & 0.061 & -0.061 & 0.122 \\
\hline
\end{tabular}


In Figure 3, a comparison of the deviation of roundness error produced under the different flushing conditions across the six depths were plotted.

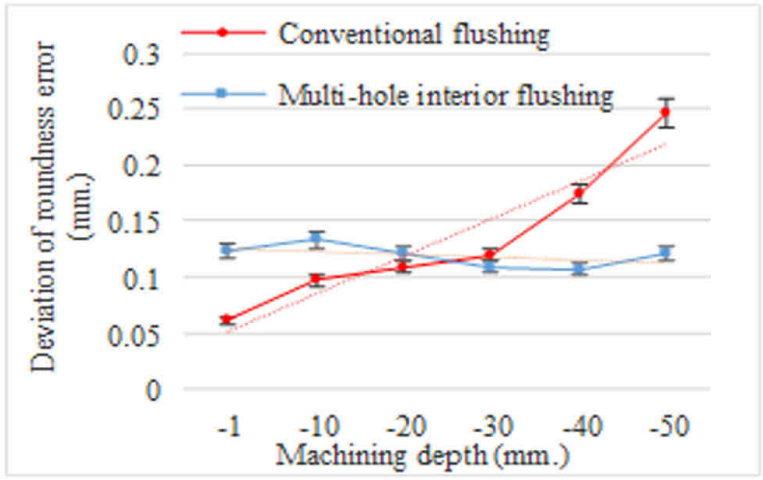

Fig. 3. The comparison of the deviation of roundness error produced under the different flushing conditions against machining depth.

It is observed that with conventional flushing the deviation of the roundness error increases continuously with the machining depth up to $50 \mathrm{~mm}$. In conventional flushing coupled with electrode rotation, the debris particles of material are moving out slowly from the machining gap and formation of secondary spark phenomena between the debris particles and side wall of the hole. As machining depth is increased, long-term effects of the secondary spark phenomena result in roundness error of the hole in higher depth [1]. In addition, it might be due to improper flushing at higher depths, as the debris particles are irregularly distributed on the side of wall of the hole leading to roundness error along the depth of hole. However, when using the multihole interior flushing electrode, a more stable roundness was observed. It is clear that the deviation of roundness error is slightly decreased, a cylindricity deviation only occurred due to the flushing as the multi-hole interior electrode is flowed out of small gap between electrode and side of wall of the hole to remove debris particles continuously. In addition, the electrode rotation during EDM deep hole process promotes cleaning of the debris in the machining gap. Therefore, the deviation of roundness error is uniformly changed. The $3 \mathrm{D}$ view measurement of roundness from 3D laser scanning surface roughness is shown in Figure 4.

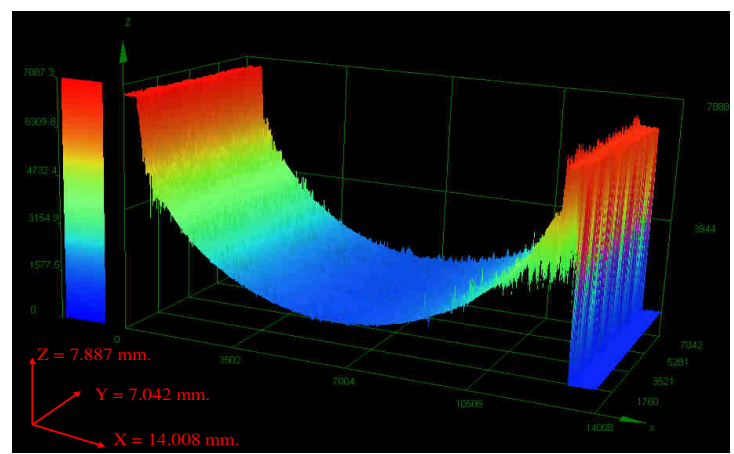

Fig. 4. $3 \mathrm{D}$ view measurement of roundness from $3 \mathrm{D}$ laser scanning surface roughness.

\subsection{Gap clearance}

For investigation of dimensional accuracy, the gap clearance is another important quality. Figure 5 shows the values of gap clearance with different flushing conditions. The electrode rotation effect at $105 \mathrm{rpm}$ was investigated. It is clear that for each condition the gap clearance increases towards the half-way depth and then narrows towards the finish. As such, the characteristic shape of the machined hole was concave. The figure also demonstrates that when using conventional electrode by side flushing the gap clearance is increased and that the gap clearance increase becomes pronounced with the depth of hole. However, the electrode rotation effect coupled with side flushing causes a decrease in gap clearance. Moreover, using the multi-hole interior flushing with rotational electrode causes a cylindrical shape in gap clearance. It is explained through a reduction in debris build up within the machining gap, and by a more uniform distribution of debris from the multi-hole flushing with rotational electrode during the EDM deep hole process [7]. This means that a more powerful flushing technique is achieved with the newly purposed multi-hole interior flushing technique on dimensional accuracy like roundness error and gap clearance, respectively. The measurement of gap clearance from 3D handy laser scanning is shown in Figure 6.

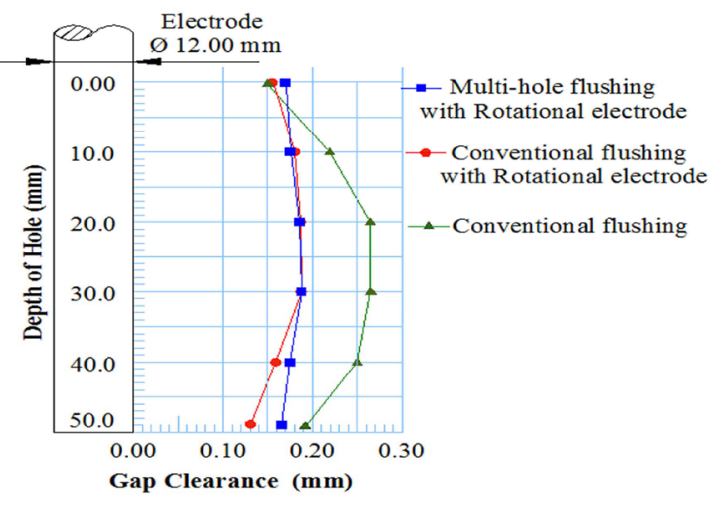

Fig. 5 Effect of flushing condition on gap clearance characteristic.

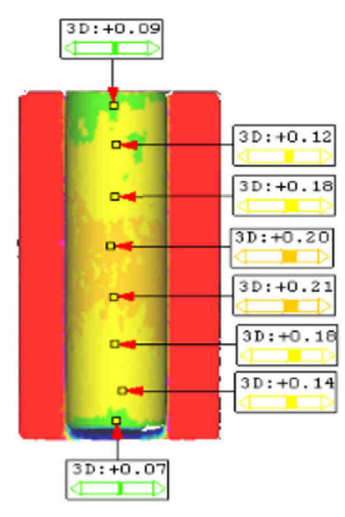

a)

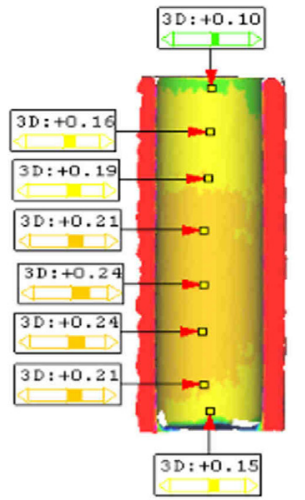

b)
Fig. 6. Measurement of gap clearance profiles was examined using 3D handy laser scanning. a) Multi-hole flushing with rotational electrode b) Conventional flushing. 


\section{Conclusion}

This paper investigates the dimensional accuracy characteristics of EDM deep holes produced by a newly purposed multi-hole interior flushing technique on AISI P20 tool steel like roundness error and gap clearance, respectively. This study shows that:

1. The multi-hole interior flushing with electrode rotation improved the deviation of roundness error due to improved flushing.

2. When using multi-hole interior flushing with rotational electrode causes the cylindrical shape in gap clearance.

3. A more powerful flushing technique is achieved with a newly purposed multi-hole interior flushing technique on dimensional accuracy like roundness error and gap clearance, respectively.

\section{Acknowledgment}

The authors acknowledge the financial support provided by Faculty of Engineering, King Mongkut's Institute of Technology Ladkrabang and Rajamangala University of Krungthep were thanked for providing facilities for testing.

\section{References}

1. V. K. Meena, M. S. Azed, S. Mitra, Int. J. Machining and Machinability of Material. V 12, 4 (2012)

2. M. Risto, R. Haas, M. Munz, Proceeding CIRP of ISEM XVIII. V 42, (2016), 127-134

3. M. N. Islam, N. H. Rafai, S. S. Subramanian, Proceeding of the WCE. V III, (2010)

4. M. M. Makenzi, B. W. Ikua, Proceeding of the MECSRI 2012. V 4, (2012)

5. J. S. Soni, G. Chakraverti, Ind. J. Eng. Mat. Sci. V 1, pp. 127-134 (1994)

6. C. Diver, J. Atkinson, H. J. Helml, L. Li, J. Mater. Process. Technol. V 169 (2005) 427-436

7. S. Chuvaree, K. Kanlayasiri, Proceeding of International conference on ICMM 2018. 